\title{
Differential Contribution of Constituent Metal lons to the Cytotoxic Effects of Fast-Dissolving Metal-Oxide Nanoparticles
}

\author{
Jiyoung Jeong ${ }^{\dagger}$, Sung-Hyun Kim ${ }^{\dagger}$, Seonghan Lee, Dong-Keon Lee, Youngju Han, \\ Soyeon Jeon and Wan-Seob Cho*
}

Laboratory of Toxicology, Department of Medicinal Biotechnology, College of Health Sciences, Dong-A University, Busan, South Korea

OPEN ACCESS

Edited by:

Yun Suk Huh,

Inha University, South Korea

Reviewed by:

Yong-Hoon Lee,

Inhalation Toxicity Research Center

Occupational Safety and Health

Research Institute (OSHRI),

South Korea

Beum-Soo An,

Pusan National University,

South Korea

*Correspondence:

Wan-Seob Cho

wcho@dau.ac.kr

tThese authors have contributed equally to this work.

Specialty section: This article was submitted to

Predictive Toxicology,

a section of the journal

Frontiers in Pharmacology

Received: 15 November 2017 Accepted: 05 January 2018

Published: 22 January 2018

Citation:

Jeong J, Kim S-H, Lee S, Lee D-K, Han Y, Jeon S and Cho W-S (2018)

Differential Contribution of Constituent

Metal lons to the Cytotoxic Effects of Fast-Dissolving Metal-Oxide

Nanoparticles.

Front. Pharmacol. 9:15.

doi: 10.3389/fphar.2018.00015
The main mechanism of toxicity for fast-dissolving nanoparticles (NPS) is relatively simple as it originates from the intrinsic toxicity of their constituent elements rather than complicated surface reactivity. However, there is little information about the compared toxicity of fast-dissolving NP and its constituent ion, which is essential for understanding the mechanism of NP toxicity and the development of a structure-toxicity relationship (STR) model. Herein, we selected three types of fast-dissolving metaloxide NPs (CoO, $\mathrm{CuO}$, and $\mathrm{ZnO})$ and constituent metal chlorides $\left(\mathrm{CoCl}_{2}, \mathrm{CuCl}_{2}\right.$, and $\mathrm{ZnCl}_{2}$ ) to compare dose-response curves between NP and its constituent metal. These materials were treated relevant cell lines for inhalation setting (i.e., differentiated THP-1 cells for macrophages and A549 cells for alveolar epithelial cells) and cytotoxicity as an endpoint was evaluated at $24 \mathrm{~h}$ post-incubation. The results showed that $\mathrm{CoO}$ and $\mathrm{CuO}$ NPs in both cell types showed similar patterns of dose-response curves and cytotoxic potential compared to that of their respective metal chloride. On the other hand, ZnO NPs in both cell types showed a completely different dose-response curve compared to that of $\mathrm{ZnCl}_{2}: \mathrm{ZnO} \mathrm{NPs}$ showed modest slope and much less potential for cytotoxicity compared to that of $\mathrm{ZnCl}_{2}$. These results imply that fastdissolving metal-oxide NPs are not always have similar dose-response curves and toxic potentials compared to their constituent metal chlorides and this may be due to the differential mechanism of intracellular uptake of these substances and their interaction with intracellular detoxification molecules. Further investigations are needed for the use of toxic potential of metal ions as a predicting factors of fast-dissolving NPs toxicity. In addition, chelating agent specific for dissolved metal ions can be applied for the treatment of these fast-dissolving NPs.

Keywords: A549, cytotoxicity, dose-response, fast-dissolving nanoparticle, THP-1, uptake

\section{INTRODUCTION}

Metal-oxide nanoparticle (NP) is one of the major types of nanomaterials, which is used for industrial as well as biomedical applications. As the number and production volume of NPs has increased, so have concerns about their toxicity exponentially increased in recent years. Inhalation, compared to other routes of exposure, has a much higher risk to humans because of the high 
deposition rate in the alveoli, which have limited clearance mechanisms. Thus, inhalation of metal-oxide NPs can cause various types of acute and chronic lung injuries (Oberdorster et al., 2005; Cho et al., 2010). With exponential increases in the types of NPs and safety concerns associated with them, there is an urgent need for the development of prescreening tools for NP safety using a structure-toxicity relationship (STR) model (Puzyn et al., 2009). The first step for a STR model is qualitative and quantitative evaluation of the structural parameters related with the toxicity of a NP.

Among various physicochemical properties of NPs, biopersistence or durability is one of the key determinants of its toxic potential (Donaldson et al., 2013; Braakhuis et al., 2014). NPs in most cases are minimally dissolving under normal physiological conditions but some NPs have shown to be dissolving to a significant degree when dispersed in acidic physiological conditions such as gastric fluid and lysosomal fluid (Cho et al., 2012b, 2013b). Although more studies are needed for defining the degrees of dissolution, previous studies including our own have shown that $\mathrm{CoO}$, $\mathrm{CuO}$, and $\mathrm{ZnO}$ NPs were almost completely dissolved within $24 \mathrm{~h}$ under acidic physiological conditions. These fast-dissolving NPs were ranked in a high-toxicity group compared to the less soluble $\mathrm{NPs}$ such as $\mathrm{CeO}_{2}, \mathrm{Co}_{3} \mathrm{O}_{4}$, $\mathrm{Cr}_{2} \mathrm{O}_{3}, \mathrm{NiO}$, and $\mathrm{TiO}_{2}$ (Rushton et al., 2010; Cho et al., 2012b; Jeong et al., 2015; Liu et al., 2015). In addition, our previous studies have shown that the toxicity of fast-dissolving metal-oxide NPs was closely related with the intrinsic toxic potential of its constituent metal ions (Cho et al., 2012b, 2013a). Although the central mechanism of toxicity for fast-dissolving NPs is the intrinsic toxicity of its constituent elements rather than surface reactivity, information comparing the toxic potential of fast-dissolving NPs and its constituent ion is lacking. This knowledge is essential for understanding the mechanism of toxicity and the development of prescreening tools for fast-dissolving NPs.

The comparison of in vivo toxic potential of NP and its constituent metal ion may be more useful than in vitro assays. However, the direct use of the comparative in vivo toxicity data between NPs and its constituent metal ion would be complicated by several limitations such as differences in deposition site (i.e., metal ions usually deposit in the upper respiratory tract in the inhalation setting, while NPs have high deposition rate in the lower respiratory tract or alveoli) and extrapulmonary translocation (i.e., metal ions have higher extrapulmonary translocation than NPs). In this regard, the in vitro comparison of toxic potential using relevant cell lines under inhalation condition can overcome these limitations and provide important information for the STR modeling of fast-dissolving NPs. Herein, we investigated the differential cytotoxicity and levels of pro-inflammatory cytokines between fastdissolving NPs and their constituent metal ions using relevant cell lines for inhalation settings: macrophages-like (differentiated) THP-1 cells and alveolar epithelial cell-like A549 cells.

\section{MATERIALS AND METHODS}

\section{Physicochemical Characterization of NPs and Metal Chlorides}

Based on our previous studies, CoO NP (NanoAmor, Houston, TX, United States), CuO NP (Sigma-Aldrich, St. Louis, MO, United States), and ZnO NP (NanoScale Corporation, Manhattan, KS, United States) were selected as representative fast-dissolving high-toxicity NPs, while $\mathrm{Co}_{3} \mathrm{O}_{4} \mathrm{NP}$ (NanoAmor) and $\mathrm{TiO}_{2} \mathrm{NP}$ (NanoAmor) were selected as representative low-solubility high-toxicity NP and low-solubility low-toxicity NP, respectively (Cho et al., 2010; Jeong et al., 2015). Metal chlorides $\left(\mathrm{CoCl}_{2}, \mathrm{CuCl}_{2}\right.$, and $\mathrm{ZnCl}_{2} ;$ Sigma-Aldrich) were used for the constituent metal ions. The primary size of NPs was measured using a transmission electron microscope (TEM; JEOL, Tokyo, Japan) and the hydrodynamic size of NPs dispersed in various media including distilled water (DW) and cell culture media was measured using a Zetasizer-Nano ZS (Malvern, Malvern Hills, United Kingdom), as previously described (Jeong et al., 2015). The surface areas of NPs were measured using Micromeritics Tristar 3000 analyzer (Micromeritics, Ltd., Bedfordshire, United Kingdom) for $\mathrm{CuO}$ and $\mathrm{ZnO}$, or ASAP 2420 (Micromeritics, Ltd.) for CoO. The Brunauer-Emmett-Teller (BET) method was used to calculate the surface area for both Micromeritics instruments. The levels of endotoxin contamination were measured at $500 \mu \mathrm{g} / \mathrm{mL}$ of NP in PBS, the highest dose used in this study, using an endpoint chromogenic Limulus amebocyte lysate (LAL) assay kit (Cambrex, Walkersville, MD, United States).

\section{Dissolution Assay for NPs}

The dissolution of NPs was measured in artificial lysosomal fluid ( $\mathrm{pH}$ 5.5) or PBS ( $\mathrm{pH} 7.4$ ) as previously described (Jeong et al., 2015). Briefly, NPs were dispersed in each medium at $100 \mu \mathrm{g} / \mathrm{mL}$ and incubated for $24 \mathrm{~h}$ at room temperature with continuous agitation. Then, three rounds of centrifugation at $15000 \times g$ for 30 min were performed to collect the NP-free supernatant and the absence of NP was confirmed by dynamic light scattering analysis using a Zetasizer-Nano ZS (Malvern). The concentration of metal ions in the supernatant was measured using inductively coupled plasma-optical emission spectrometry (ICP-OES) (Optima 8300, PerkinElmer, Shelton, CT, United States) by the Center for Collaborative Instruments at Dong-A University. The dissolution was calculated as the percentage of dissolved metal concentration compared to the initial mass of metal in the NP dispersion.

\section{Preparation of NPs and Metal Chlorides for Cell Culture}

Because NP showed agglomerations in culture medium as shown in Table 1, it was pre-dispersed with fetal bovine serum (FBS) as described in our previous study (Cho et al., 2013a). Briefly, the stock solution of NP was dispersed in DW at $5000 \mu \mathrm{g} / \mathrm{mL}$ and sonicated with $28 \mathrm{KHz}$ operation frequencies and $400 \mathrm{~W}$ output power for $5 \mathrm{~min}$ in a bath sonicator (Saehan-Sonic, Seoul, South Korea). Then FBS was added 5\% (for A549 cells) or 10\% (for THP-1 cells) of working volume and sonicated with bath 
TABLE 1 | Physicochemical properties of NPs.

\begin{tabular}{|c|c|c|c|c|c|}
\hline NPs & $\mathrm{CoO}$ & CuO & $\mathrm{ZnO}$ & $\mathrm{Co}_{3} \mathrm{O}_{4}$ & $\mathrm{TiO}_{2}$ \\
\hline Primary size (nm) & $75.0 \pm 2.4$ & $28.5 \pm 0.7$ & $16.5 \pm 0.4$ & $33.8 \pm 2.1$ & $39.9 \pm 1.4$ \\
\hline Surface area $\left(\mathrm{m}^{2} \mathrm{~g}\right)$ & 8.5 & 29 & 48.2 & 35.8 & 27.5 \\
\hline \multicolumn{6}{|c|}{ Hydrodynamic size $(\mathrm{nm})$ in } \\
\hline DW & $493 \pm 10$ & $176 \pm 1.5$ & $592 \pm 21$ & $153 \pm 3.5$ & $472 \pm 10$ \\
\hline RPMI-1640 & $116 \pm 13$ & $192 \pm 4.6$ & $296 \pm 14$ & $164 \pm 3.9$ & $517 \pm 14$ \\
\hline DMEM & $335 \pm 57$ & $188 \pm 5.3$ & $491 \pm 51$ & $170 \pm 6.2$ & $527 \pm 25$ \\
\hline \multicolumn{6}{|l|}{ Polydispersity in } \\
\hline DW & $0.35 \pm 0.01$ & $0.19 \pm 0.02$ & $0.55 \pm 0.04$ & $0.20 \pm 0.02$ & $0.41 \pm 0.03$ \\
\hline RPMI-1640 & $0.38 \pm 0.02$ & $0.18 \pm 0.02$ & $0.58 \pm 0.02$ & $0.22 \pm 0.01$ & $0.53 \pm 0.06$ \\
\hline DMEM & $0.76 \pm 0.01$ & $0.18 \pm 0.00$ & $0.81 \pm 0.04$ & $0.21 \pm 0.01$ & $0.35 \pm 0.01$ \\
\hline \multicolumn{6}{|c|}{ Zeta potential $(\mathrm{mV})$ in } \\
\hline DW & $22.27 \pm 0.20$ & $38.80 \pm 0.90$ & $-8.74 \pm 1.57$ & $26.40 \pm 0.42$ & $19.30 \pm 0.50$ \\
\hline RPMI-1640 & $-21.40 \pm 0.52$ & $-21.33 \pm 0.88$ & $-22.30 \pm 0.49$ & $-20.67 \pm 0.69$ & $-23.40 \pm 0.53$ \\
\hline DMEM & $-21.50 \pm 0.52$ & $-21.17 \pm 0.54$ & $-20.57 \pm 0.75$ & $-20.07 \pm 0.52$ & $-22.50 \pm 0.55$ \\
\hline Endotoxin (U/mL) & $<0.1$ & $<0.1$ & $<0.1$ & $<0.1$ & $<0.1$ \\
\hline Solubility (\%) in ALF & 95.27 & 100 & 99.06 & 11.46 & 0 \\
\hline Solubility (\%) in PBS & 1.34 & 1.71 & 2.82 & 0.02 & 0 \\
\hline
\end{tabular}

DW, distilled water; ALF, artificial lysosomal fluid; PBS, phosphate-buffered saline.

sonicator (Saehan-Sonic) for $5 \mathrm{~min}$. FBS-free culture medium was then added for working concentrations $(0-500 \mu \mathrm{g} / \mathrm{mL})$. Because metal chlorides showed precipitation in Dulbecco's Modified Eagle's Medium (DMEM; GIBCO, Grand Island, NY, United States), phosphate-free DMEM (GIBCO), which showed no precipitation, was used as the culture medium for metal chlorides.

\section{Cell Culture}

Because the primary target cell for inhaled particle is alveolar macrophages and activated macrophages by NPs can damage alveolar epithelial cells by releasing various inflammatory mediators and cytotoxic materials, we selected relevant cell lines for inhalation settings as macrophage-like (differentiated) THP-1 cells (American Type Culture Collection, Manassas, VA, United States) and alveolar epithelial cell-like A549 cells (European Collection of Animal Cell Cultures, Salisbury, United Kingdom). Both cell lines were cultured and maintained as described in our previous study (Cho et al., 2013a).

\section{Treatment of Cells with NPs or Metal Chlorides and Evaluation of Cytotoxicity}

Because THP-1 cells are monocytic cells, they differentiated to macrophage-like cells with phorbol myristate acetate (PMA; Sigma-Aldrich) treatment. Briefly, differentiated THP-1 cells were prepared by seeding at $5 \times 10^{5}$ cells $/ \mathrm{mL}$ with $10 \mathrm{ng} / \mathrm{mL}$
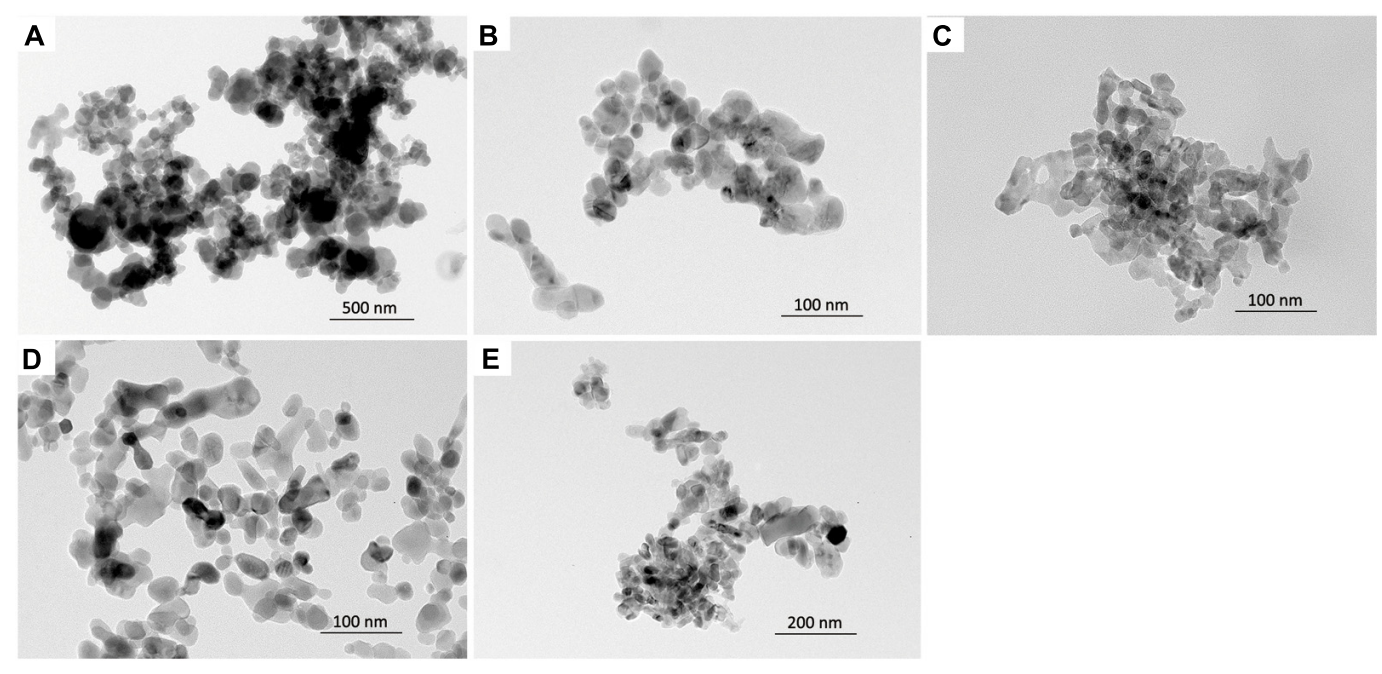

FIGURE 1 | The morphology of NPs observed by a transmission electron microscopy. (A) CoO NP, (B) CuO NP, (C) ZnO NP, (D) Co $3 \mathrm{O}_{4}$ NP, and (E) TiO 2 NP. 
of PMA in 96-well plates and culturing for 2 days. A549 cells were seeded at $2 \times 10^{5}$ cells $/ \mathrm{mL}$ in 96 -well plates and incubated overnight for $80 \%$ confluency. THP-1 cells or A549 cells were then washed three times with pre-warmed PBS and were treated with NPs dispersed in culture medium at various concentrations from 0 to $500 \mu \mathrm{g} / \mathrm{mL}$. After $24 \mathrm{~h}$ incubation, the supernatant was collected for measurement of pro-inflammatory cytokines, and cells were washed three times with pre-warmed PBS to avoid or minimize interference on the cytotoxicity assay by NPs or dissolved metal ions (Rosslein et al., 2015). Then, $100 \mu \mathrm{L}$ of fresh complete medium was added with $20 \mu \mathrm{L}$ of 3-(4,5-dimethylthiazol-2-yl)-5(3-carboxymethoxyphenyl)-2-(4-sulfophenyl)-2H-tetrazolium (MTS) solution (Promega, Madison, WI, United States). After $2 \mathrm{~h}$ incubation at $37^{\circ} \mathrm{C}$ in a $\mathrm{CO}_{2}$ incubator, the supernatant was transferred to clean plates to minimize colorimetric interference by cells containing NPs and absorbance was measured at $490 \mathrm{~nm}$. To compare the dose-response and potential of cytotoxicity between fast-dissolving NPs and its respective metal ions, the masses of treatment doses were converted into molar concentrations.

\section{Measurement of Levels of Pro-inflammatory Cytokines}

The pro-inflammatory cytokines levels in the cell-culture supernatant were measured using an enzyme-linked immunosorbent assay (ELISA) kit. In differentiated THP-1 cells, interleukin-1 $\beta$ (IL-1 $\beta$ ) was measured to evaluate the effect of NPs on the activation of the inflammasome (Yazdi et al., 2010). On the other hand, IL-8 was measured in A549 cells to evaluate the role of NPs and metal chlorides on the stimulation of lung epithelial cells. Both ELISA kits were purchased from the R\&D systems (Duoset kit, Minneapolis, MN, United States). Based on the cell viability data, more than three doses were selected for the measurement of IL- $1 \beta$ in THP- 1 cells, the selected doses were 5,10, and $20 \mu \mathrm{g} / \mathrm{mL}$ for fast-dissolving NPs and metal chlorides; and 25, 50, and $100 \mu \mathrm{g} / \mathrm{mL}$ for control NPs $\left(\mathrm{Co}_{3} \mathrm{O}_{4}\right.$
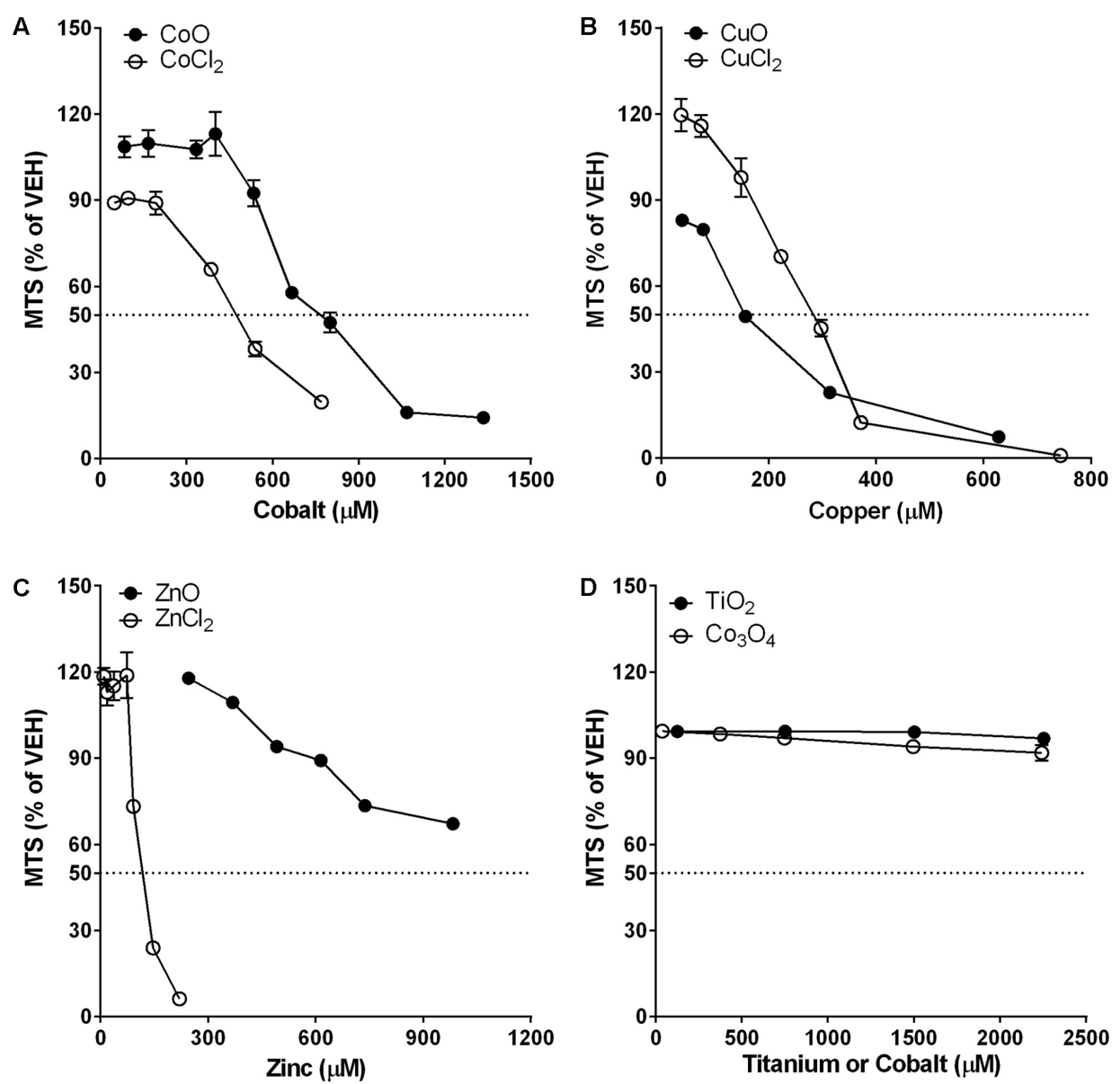

FIGURE 2 | Comparison of dose-response curves of metal-oxide NPs and their respective constituent metal chlorides in differentiated THP-1 cells. Cytotoxicity was measured by MTS assay. Note that the mass doses were converted into molar concentrations. (A) CoO NP showed a similar trend in the dose-response curve but less cytotoxic potential than $\mathrm{CoCl}_{2}$. (B) CuO NP showed a similar trend in the dose-response curve but higher cytotoxic potential than $\mathrm{CuCl}_{2}$. (C) $\mathrm{ZnO}$ NP showed a completely different trend in the dose-response curve with much less cytotoxic potential than $\mathrm{ZnCl}_{2}$. (D) Biopersistent $\mathrm{TiO}_{2}$ and $\mathrm{Co}_{3} \mathrm{O}_{4} \mathrm{NPs}$ showed no cytotoxicity within the tested doses ( $<180 \mu \mathrm{g} / \mathrm{mL} ; 2254 \mu \mathrm{M}$ for $\mathrm{TiO}_{2}$ and $2243 \mu \mathrm{M}$ for $\left.\mathrm{CO}_{3} \mathrm{O}_{4}\right)$. Values are mean \pm SEM from eight independent experiments. 
and $\mathrm{TiO}_{2}$ ). Likewise, for A549 cells, the selected doses were 1-50 $\mu \mathrm{g} / \mathrm{mL}$ for fast-dissolving NPs and metal chlorides; 25, 50, and $100 \mu \mathrm{g} / \mathrm{mL}$ for control NPs $\left(\mathrm{Co}_{3} \mathrm{O}_{4}\right.$ and $\left.\mathrm{TiO}_{2}\right)$. The mass doses were converted into the molar concentrations.

\section{Treatment of Cells with Chelated Dissolved Metal lons}

To evaluate the role of dissolved metal ions in the cytotoxicity, cells were treated with solubilized ions followed by chelation, as described in our previous study with slight modification (Cho et al., 2012a). Briefly, the stock solution of metal chlorides at $5 \mathrm{mg} / \mathrm{mL}$ in DW were incubated with $50 \mathrm{mg} / \mathrm{mL}$ Chelex 100 beads (Sigma-Aldrich) and mixed for $4 \mathrm{~h}$ at room temperature with continuous agitation. The beads were then removed by centrifugation at $15000 \times g$ for $15 \mathrm{~min}$. The collected supernatant was diluted to the final working concentration $(100 \mu \mathrm{g} / \mathrm{mL})$ with cell culture medium and treated to A549 or differentiated THP-1 cells.

\section{Statistical Analysis}

Data were expressed as mean $\pm \operatorname{SEM}(n=8)$. We analyzed statistical differences using one-way analysis of variance (ANOVA) followed by post hoc Tukey's pairwise comparisons using a GraphPad Prism V6.0 (GraphPad Software, San Diego, CA, United States). A $p$ value less than 0.05 was considered statistically significant.

\section{RESULTS}

\section{Physicochemical Properties of the NPs}

The physicochemical properties of NPs are presented in Table $\mathbf{1}$. All NPs were less than $100 \mathrm{~nm}$ in size, as measured by TEM
(Figure 1). The hydrodynamic size of NPs in DW showed that all types of NPs were agglomerated with a size range 153-592 nm: $\mathrm{Co}_{3} \mathrm{O}_{4} \mathrm{NP}$ showed the least agglomeration, while the $\mathrm{ZnO}$ NP showed the most. The hydrodynamic size of NPs in the culture medium showed that the pre-dispersion of NPs using FBS significantly reduced agglomeration, which resulted in size ranges improved or comparable to those in DW. The surface charge measured by zeta potential showed that ZnO NP in DW was negative, while the other NPs were positive. However, the zeta potential of NPs in culture medium showed that all types of NPs had negative zeta potential with similar size ranges about $-20 \mathrm{mV}$. The LAL assay showed that all NPs had endotoxin levels less than the limit of detection (LOD; $0.1 \mathrm{U} / \mathrm{mL}$ ). The dissolution study showed that incubation of fast-dissolving NPs $(\mathrm{CoO}, \mathrm{CuO}$, and $\mathrm{ZnO}$ ) in artificial lysosomal fluid ( $\mathrm{pH}$ 5.5) for $24 \mathrm{~h}$ resulted dissolution more than 95\%, while $\mathrm{Co}_{3} \mathrm{O}_{4}$ and $\mathrm{TiO}_{2}$ NPs had 11.46 and $0 \%$ dissolution, respectively. However, all NPs dispersed in PBS showed less than 3\% dissolution.

\section{Differential Cytotoxic Potential between NPs and Metal Chlorides in Differentiated THP-1 Cells}

The dose-response curves of NPs and metal chlorides are presented in Figure 2. The dose-response curves of CoO NP vs. $\mathrm{CoCl}_{2}$ and $\mathrm{CuO} \mathrm{NP}$ vs. $\mathrm{CuCl}_{2}$ on comparison showed similar trends but slightly different cytotoxic potential. CoO NP showed lower cytotoxic potential than $\mathrm{CoCl}_{2}$, while $\mathrm{CuO} \mathrm{NP}$ showed higher cytotoxic potential than $\mathrm{CuCl}_{2}$. The $\mathrm{EC}_{50}$ value for $\mathrm{CoO}$ $\mathrm{NP}$ and $\mathrm{CoCl}_{2}$ was $775 \mu \mathrm{M}(58 \mu \mathrm{g} / \mathrm{mL})$ and $475 \mu \mathrm{M}(62 \mu \mathrm{g} / \mathrm{mL})$, respectively. The $\mathrm{EC}_{50}$ value of $\mathrm{CuO} \mathrm{NP}$ and $\mathrm{CuCl}_{2}$ was $155 \mu \mathrm{M}$ $(12 \mu \mathrm{g} / \mathrm{mL})$ and $284 \mu \mathrm{M}(38 \mu \mathrm{g} / \mathrm{mL})$, respectively. Unlike CoO and $\mathrm{CuO}$ NPs, ZnO NP showed a completely different trend of the dose-response curve when compared to $\mathrm{ZnCl}_{2}$. The cytotoxic
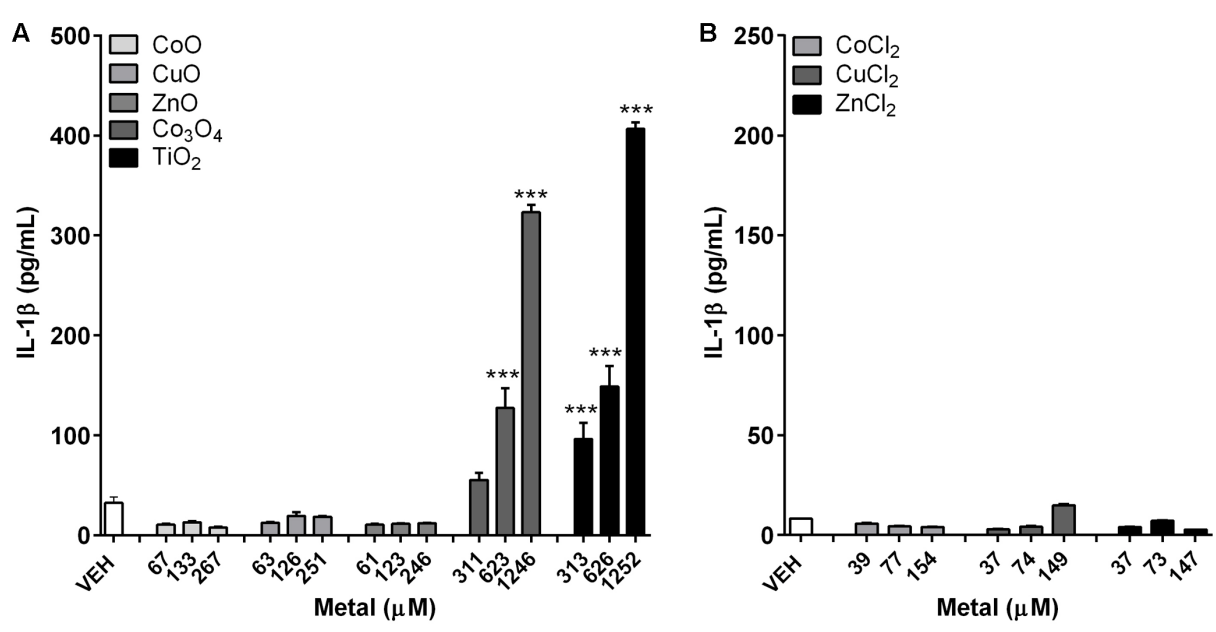

FIGURE 3 | Concentrations of IL-1 $\beta$ in differentiated THP-1 cells after treatment with metal-oxide NPs or metal chlorides. (A) Fast-dissolving NPs showed no significant increase, while biopersistent $\mathrm{Co}_{3} \mathrm{O}_{4}$ and $\mathrm{TiO}_{2} \mathrm{NPS}$ showed significant increase in a dose-dependent manner. (B) Metal chlorides showed no significant increase. The selected doses were 5, 10, and $20 \mu \mathrm{g} / \mathrm{mL}$ for fast-dissolving NPs and metal chlorides; and 25, 50, and 100 $\mu \mathrm{g} / \mathrm{mL}$ for biopersistent control NPs $\left(\mathrm{Co}_{3} \mathrm{O}_{4}\right.$ and $\left.\mathrm{TiO}_{2}\right)$. Note that the doses were converted into molar concentrations. Values are mean $\pm \mathrm{SEM}$ from eight independent experiments. $* * * p<0.001$ vs. vehicle control $(\mathrm{VEH})$. 

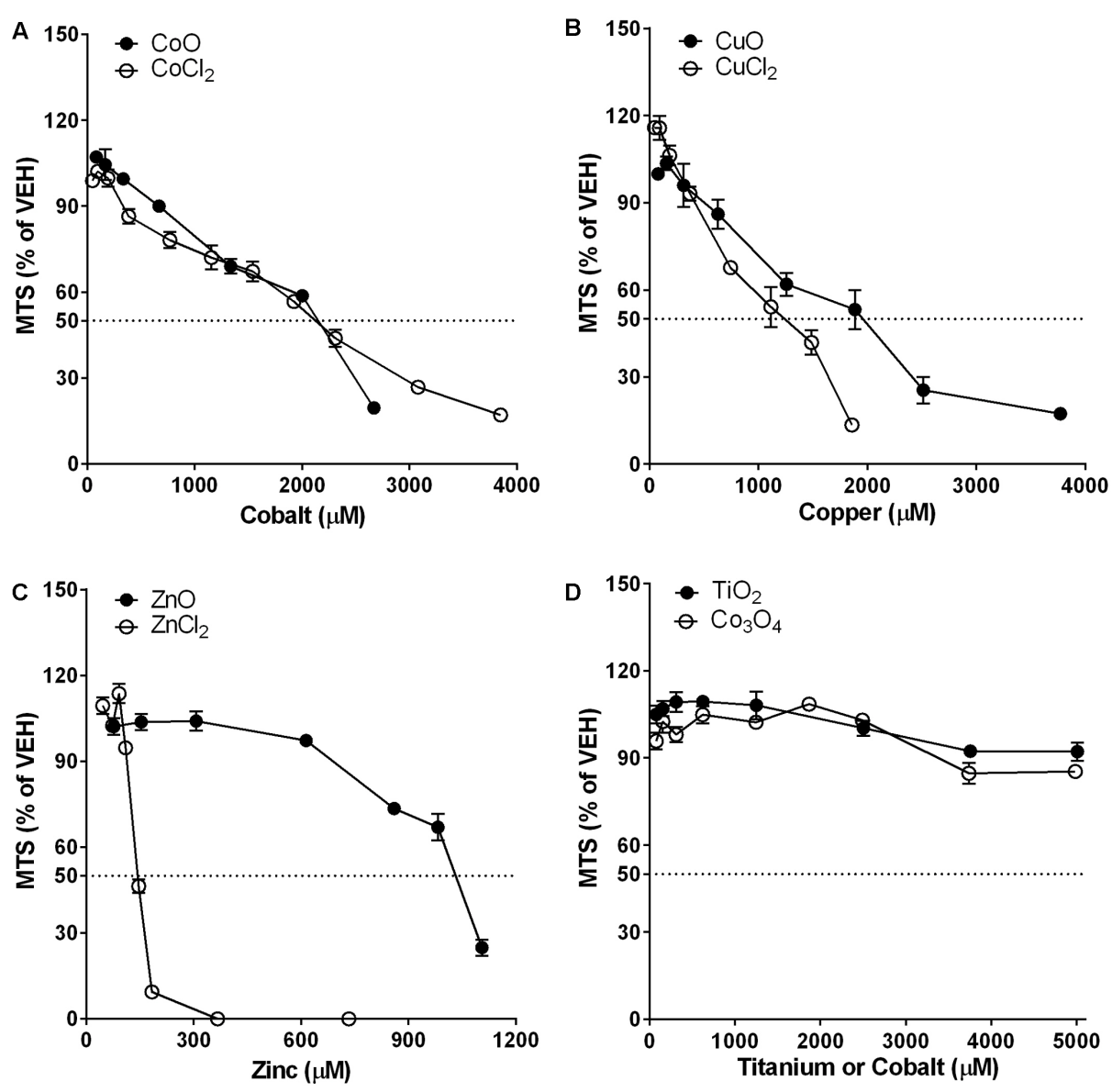

FIGURE 4 | Comparison of dose-response curves of metal-oxide NPs and their respective constituent metal chlorides in A549 cells. Cytotoxicity was measured by MTS assay. Note that the mass doses were converted into molar concentrations. (A) CoO NP showed a similar trend in the dose-response curve and almost identical cytotoxic potential compared to $\mathrm{CoCl}_{2}$. (B) CuO NP showed a similar trend in the dose-response curve but less cytotoxic potential than $\mathrm{CuCl}_{2}$. (C) $\mathrm{ZnO} \mathrm{NP}$ showed a completely different trend in the dose-response curve with much less cytotoxic potential than $\mathrm{ZnCl}_{2}$. (D) Biopersistent $\mathrm{TiO}_{2}$ and $\mathrm{Co}_{3} \mathrm{O}_{4} \mathrm{NPs}_{3}$ showed no cytotoxicity within the tested doses $\left(<400 \mu \mathrm{g} / \mathrm{mL} ; 5008 \mu \mathrm{M}\right.$ for $\mathrm{TiO}_{2}$ and $4983 \mu \mathrm{M}$ for $\left.\mathrm{Co}_{3} \mathrm{O}_{4}\right)$. Values are mean \pm SEM from eight independent experiments.

potential of $\mathrm{ZnO} N P$ was much less than that of $\mathrm{ZnCl}_{2}$. The $\mathrm{EC}_{50}$ value of $\mathrm{ZnO} N P$ was higher than $983 \mu \mathrm{M}(80 \mu \mathrm{g} / \mathrm{mL})$, while $\mathrm{EC}_{50}$ value of $\mathrm{ZnCl}_{2}$ was $120 \mu \mathrm{M}(16 \mu \mathrm{g} / \mathrm{mL})$. Biopersistent $\mathrm{TiO}_{2}$ and $\mathrm{Co}_{3} \mathrm{O}_{4}$ NPs showed no cytotoxicity within the tested doses.

\section{Differential IL-1 $\beta$ Concentrations between Differentiated THP-1 Cells Treated with NPs and Metal Chlorides}

IL-1 $\beta$ levels showed no significant changes on treatment with either fast-dissolving $\mathrm{NPs}(\mathrm{CoO}, \mathrm{CuO}$, and $\mathrm{ZnO})$ or metal chlorides $\left(\mathrm{CoCl}_{2}, \mathrm{CuCl}_{2}\right.$, and $\left.\mathrm{ZnCl}_{2}\right)$ (Figure 3). However, the biopersistent control NPs, both $\mathrm{Co}_{3} \mathrm{O}_{4}$ and $\mathrm{TiO}_{2}$, showed significant increase in IL- $1 \beta$ levels in a dose-dependent manner (Figure 3A).

\section{Differential Cytotoxic Potential between NPs and Metal Chlorides in A549 Cells}

Cytotoxicity measured by the MTS assay in A549 cells is presented in Figure 4. Dose-response curve of $\mathrm{CoO}$ NP was overlapped with that of $\mathrm{CoCl}_{2}$, and the $\mathrm{EC}_{50}$ value for both $\mathrm{CoO} \mathrm{NP}$ and $\mathrm{CoCl}_{2}$ was $2150 \mu \mathrm{M}(161 \mu \mathrm{g} / \mathrm{mL}$ for $\mathrm{CoO}$ NPs and $279 \mu \mathrm{g} / \mathrm{mL}$ for $\mathrm{CoCl}_{2}$ ). While, $\mathrm{CuO} \mathrm{NP}$ and $\mathrm{CuCl}_{2}$ showed similar trends in their dose-response curves, the cytotoxic potential of $\mathrm{CuO} \mathrm{NP}$ was slightly less than that of $\mathrm{CuCl}_{2}$. The $\mathrm{EC}_{50}$ values for $\mathrm{CuO} \mathrm{NP}$ and $\mathrm{CuCl}_{2}$ were $1960 \mu \mathrm{M}(156 \mu \mathrm{g} / \mathrm{mL})$ and $1235 \mu \mathrm{M}(166 \mu \mathrm{g} / \mathrm{mL})$, respectively. Unlike $\mathrm{CoO}$ and $\mathrm{CuO}$ $\mathrm{NP}$, the dose-response curve of $\mathrm{ZnO} \mathrm{NP}$ was completely different compared to that of $\mathrm{ZnCl}_{2}$. The $\mathrm{EC}_{50}$ values of $\mathrm{ZnO}$ and $\mathrm{ZnCl}_{2}$ in A549 cells were $1030 \mu \mathrm{M}(84 \mu \mathrm{g} / \mathrm{mL})$ and $143 \mu \mathrm{M}(20 \mu \mathrm{g} / \mathrm{mL})$, respectively. Biopersistent $\mathrm{TiO}_{2}$ and $\mathrm{Co}_{3} \mathrm{O}_{4}$ NPs showed no significant cytotoxicity within the tested doses.

\section{Differential IL-8 Concentrations between A549 Cells Treated with NPs and Metal Chlorides}

IL-8 levels showed no significant changes on treatment with either fast-dissolving $\mathrm{NPs}(\mathrm{CoO}, \mathrm{CuO}$, and $\mathrm{ZnO})$ or biopersistent control NPs $\left(\mathrm{Co}_{3} \mathrm{O}_{4}\right.$ and $\left.\mathrm{TiO}_{2}\right)$ (Figure 5). Treatment of metal 

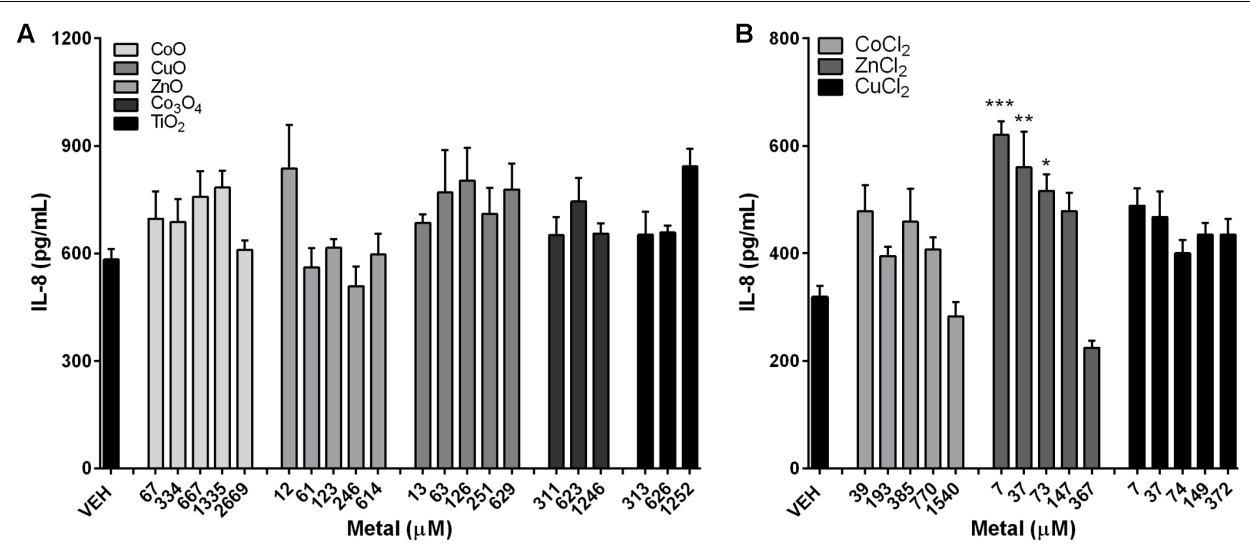

FIGURE 5 | Concentrations of IL-8 expression in the A549 cells after treatment with metal-oxide NPs or metal chlorides. IL-8 levels in A549 cells after treatment with (A) metal-oxide NPs, and (B) metal chlorides. NPs were treated at various doses ranging $1-200 \mu \mathrm{g} / \mathrm{mL}$. Note that the mass doses were converted into molar concentrations. Values are mean \pm SEM from eight independent experiments. ${ }^{*} p<0.05,{ }^{* *} p<0.01$, and $* * * p<0.001$ vs. VEH.
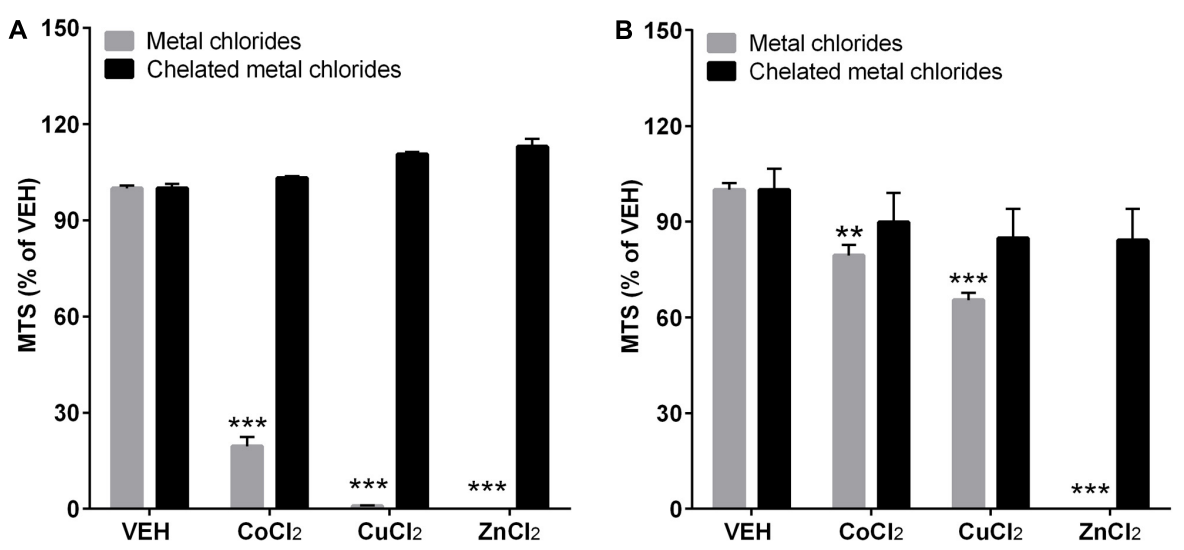

FIGURE 6 | The cytotoxicity assay after chelation of metal chlorides. The differentiated THP-1 cells (A) and A549 cells (B) were treated with or without chelation of metal ions. To chelated metal ions, Chelex 100 beads (Sigma-Aldrich) were applied to the stock solution of metal chlorides in DW and diluted to the final working concentration in cell culture media. The treated dose for both metal chlorides and chelated metal chlorides was $100 \mu \mathrm{g} / \mathrm{mL}$. Cytotoxicity was measured by MTS assay. Values are mean \pm SEM from eight independent experiments. ${ }^{* *} p<0.01$, and $* * * p<0.001$ vs. VEH.

chlorides $\left(\mathrm{CoCl}_{2}, \mathrm{CuCl}_{2}\right.$, and $\left.\mathrm{ZnCl}_{2}\right)$ also showed no biologically meaningful changes in the IL-8 levels, although $\mathrm{ZnCl}_{2}$ showed slight increases in the low and mid dose (Figure 5).

\section{Cytotoxicity of Differentiated THP-1 Cells and A549 Cells after Chelation of Metal Chlorides}

The chelation of metal chlorides showed dramatic recovery of cytotoxicity compared to non-chelated metal chlorides (Figure 6). Although metal chlorides at $100 \mu \mathrm{g} / \mathrm{mL}$ showed significant cytotoxicity in both cell lines, chelation of metals did not show any cytotoxicity at the tested dose.

\section{DISCUSSION}

Non-biopersistent fast-dissolving metal-oxide NPs such as $\mathrm{CoO}$, $\mathrm{CuO}$, and $\mathrm{ZnO}$ are generally ranked in a higher toxicity group than biopersistent metal-oxide NPs such as $\mathrm{CeO}_{2}, \mathrm{Co}_{3} \mathrm{O}_{4}, \mathrm{Cr}_{2} \mathrm{O}_{3}$, $\mathrm{NiO}$, and $\mathrm{TiO}_{2}$ because of the wide-spread to target cells and fast dissolution in the acidic lysosomal fluid like a Trojan-horse (Cho et al., 2010; Rushton et al., 2010; Liu et al., 2015). Because one of the main mechanisms of toxicity for fast-dissolving NPs is the loss in durability by the acidic lysosomal fluid inside phagolysosomes, prediction of their toxicity might be possible using the intrinsic toxic potential of their constituent ions. However, there is little known about the correspondence between the toxic potential of fast-dissolving metal-oxide NP and its constituent metal. Thus, we believe that evaluation of the differential toxic effect of NP and metal ion using an in vitro system which can mimic in vivo inhalation settings might provide better information for the mechanism of toxicity for fast-dissolving metal oxide NPs. Herein, we found that the cytotoxic potential as well as pattern of dose-response curves of fast-dissolving NPs ( $\mathrm{CoO}, \mathrm{CuO}$, and $\mathrm{ZnO}$ ) in macrophage-like THP-1 cells or alveolar epithelial cell-like A549 cells had both similarities and differences when 


\section{Exposure to cell}

\section{Cellular uptake}

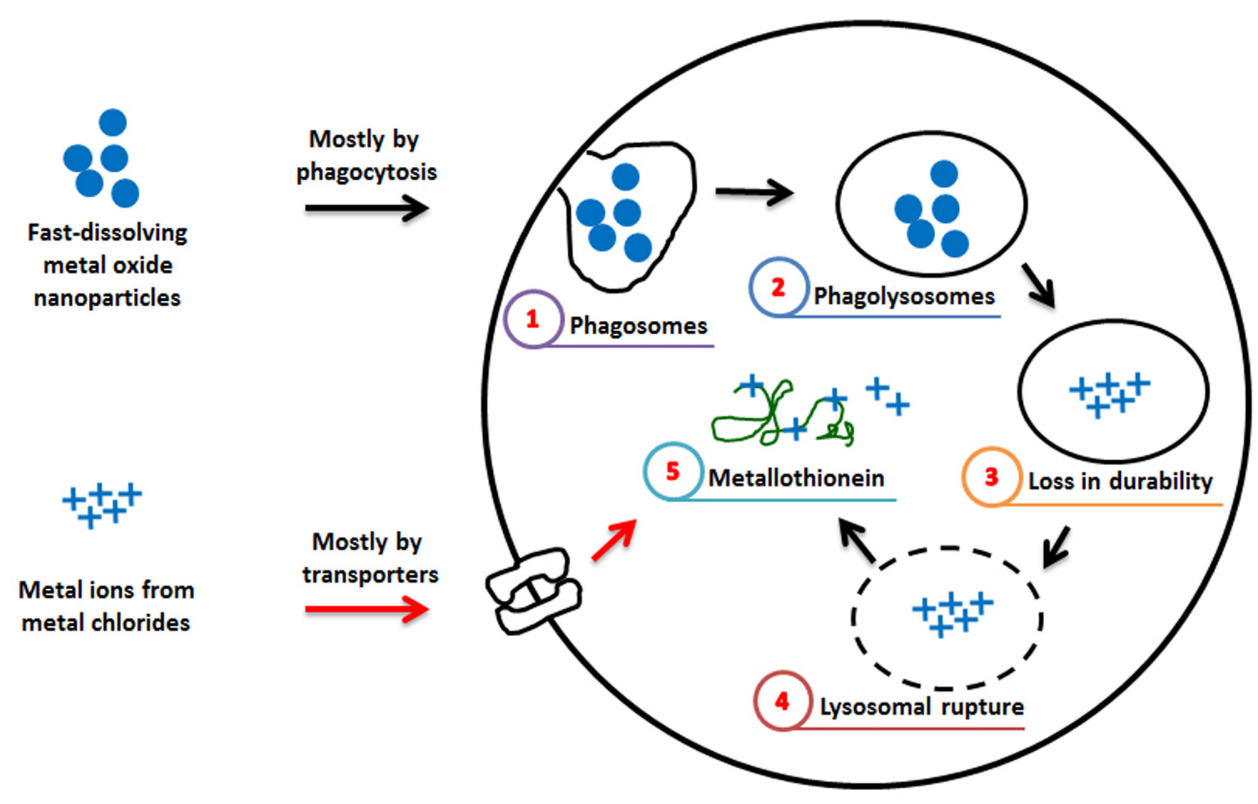

FIGURE 7 | Hypothetical diagram for the differential effect of fast-dissolving metal-oxide NPs and their respective metal chlorides. The differential cytotoxic effect of fast-dissolving metal-oxide NPs and metal ions might be due to the difference in the mechanism of intracellular uptake. NP enters mostly by phagocytosis and (1) phagosomes can fuse with lysosomes to form (2) phagolysosomes. In the acidic lysosomal fluid, fast-dissolving NP can be (3) susceptible to breakdown and its toxic metal ions can (4) rupture the lysosomal membrane. (5) In the cytosol, some of the released metal ions bind with metallothionein, while metal ions outside the cell enter mostly via transporters and (5) bind with metallothionein. The reduced cytotoxicity of $\mathrm{ZnO}$ compared to $\mathrm{ZnCl}_{2}$ might be due to $\mathrm{Zn}$-metallothionein that can act as anti-oxidant, while the comparable cytotoxicity of $\mathrm{CoO}$ vs. $\mathrm{CoCl}_{2}$ and $\mathrm{CuO}$ vs. $\mathrm{CuCl}_{2}$ might be due to Cu-metallothionein that can act as pro-oxidant, although the effect of Co-metallothionein is not known (Hahn et al., 2001).

compared to their respective constituent ions, and responses also slightly differed by the types of tested cells.

In this study, we evaluated cytotoxicity by the MTS assay, which measures mitochondrial activity. Colorimetric or fluorometric assays can be sensitive to interference by NPs or dissolved metal ions (Kroll et al., 2012). However, we minimized this interference by washing away any NPs or metal ions dispersed in culture medium before adding the MTS solution. In addition, NPs inside cells can be further excluded by collecting the cell-free supernatant prior to measure the absorbance. This modified MTS assay has many advantages compared to other methods such as microscopically observing stained cells (e.g., trypan blue exclusion assay, calcein acetoxymethyl ester staining, and neutral red staining), lactate dehydrogenase (LDH) assay, and flow cytometry. Counting dead or live cells after staining cells using a microscope can be inaccurate because NPs (e.g., black particles) can physically interfere in distinguishing colors, and omission of some dead cells due to detachment from the culture plate (Darolles et al., 2013). LDH assay can be interfered by NPs (by adsorption of formazan) or dissolved ions (by inhibition of the enzymatic reaction), which are hard to exclude in the cell culture supernatants (Holder et al., 2012). Thus, the modified MTS assay used in this study is easy and fast to perform and provides reliable results. Other methods similar to the MTS assay are Alamar Blue assay, water-soluble tetrazolium salt-1 (WST-1),
Cell Counting Kit-8 (CCK-8), and 2,3-bis-(2-methoxy-4-nitro-5sulfophenyl)-2H-tetrazolium-5-carboxanilide (XTT) assay.

The comparison of dose-responses between NP and its constituent metal ions showed similar and differential effects in both cell lines. The similar effects of $\mathrm{CoO}$ and $\mathrm{CoCl}_{2}$ were consistent with our previous study, where intratracheal instillation of $\mathrm{CoO} \mathrm{NP}$ showed similar or slightly less inflammogenic and cytotoxic potential than $\mathrm{CoCl}_{2}$ at the same molar concentration (Jeong et al., 2015). The role of dissolved ions in the toxicity of fast-dissolving NPs was further supported by a previous study which showed that less soluble micro-scale $\mathrm{CuO}$ particles had much less cytotoxicity than highly soluble nano-scale $\mathrm{CuO}$ NPs, and highly soluble nano-scale $\mathrm{CuO}$ NPs in A549 cells and HeLa S3 cells showed similar dose-response curves of cytotoxicity compared to $\mathrm{CuCl}_{2}$ at the same molar concentration (Semisch et al., 2014). The differential cytotoxic potential of NPs compared to its constituent metal chlorides by the types of cells found in this study might be due to the difference in the activity of cellular uptake as well as in the sensitivity of cell types. Endocytosis and release of dissolved metal ions inside phagolysosomes is the main toxicity mechanism of fast-dissolving NPs, while metal ions can enter cells mostly via transporters, thus fast-dissolving NPs need longer time for dissolution but has much higher intracellular metal concentrations than those of soluble ions 
(Colognato et al., 2008; Ponti et al., 2009; Semisch et al., 2014). Taking into account variation in the mechanism of cellular uptake and the resultant difference in cellular localization and concentration, the direct comparison of fast-dissolving NPs against their constituent ions might be limited.

Dissolved free-zinc from either $\mathrm{ZnO} \mathrm{NP}$ or $\mathrm{ZnCl}_{2}$ induces apoptosis or necrosis in endothelial and epithelial cells by damaging mitochondrial function followed by elevation of intracellular reactive-oxygen species (Wiseman et al., 2006; Kim et al., 2010). However, in this study, $\mathrm{ZnO} \mathrm{NP}$ in comparison to $\mathrm{ZnCl}_{2}$ showed very low toxic potential with completely different trend of dose-response curves in both cell types. The lesser cytotoxicity of $\mathrm{ZnO} \mathrm{NP}$ in comparison to $\mathrm{ZnCl}_{2}$ was also reported in Daphnia (Adam et al., 2014; Garcia-Gomez et al., 2014) and in rats (Cho et al., 2011; Amara et al., 2014).

The differential toxic effects between $\mathrm{ZnO} \mathrm{NP}$ and $\mathrm{ZnCl}_{2}$ might be due to differences in cellular uptake mechanisms and the microenvironment they encounter (Figure 7). The breakdown of $\mathrm{ZnO} \mathrm{NP}$ is initiated when it enters into acidic phagolysosomes, while ionized zinc from $\mathrm{ZnCl}_{2}$ in culture medium can enter cells immediately after treatment, mostly via specific transporters (Cho et al., 2013a). Furthermore, the free zinc localized in the cytosol stimulates metallothionein expression, and NPs have a greater potential for the stimulation of metallothionein than their component metal ion (Hahn et al., 2001; Cuillel et al., 2014; Bulcke and Dringen, 2015). Metallothionein-zinc complex can mitigate the toxicity of freezinc, which is very toxic because of its oxidation ability. However, copper can replace zinc from the metallothioneinzinc complex, thus the copper-metallothionein complex is a pro-oxidant, while the zinc-metallothionein complex is an antioxidant (Hahn et al., 2001). The variable role of metallothionein depending on the type of metal might explain why $\mathrm{ZnO} \mathrm{NP}$ has different cytotoxicity compared with $\mathrm{ZnCl}_{2}$ in contrast to $\mathrm{CoO}$ and $\mathrm{CuO}$ NPs. However, more studies are warranted to evaluate the exact mechanism of these differential toxic effects between $\mathrm{ZnO} \mathrm{NP}$ and $\mathrm{ZnCl}_{2}$.

In this study, neither fast-dissolving NPs nor metal chlorides stimulated the production of IL-1 $\beta$, while biopersistent $\mathrm{Co}_{3} \mathrm{O}_{4}$ and $\mathrm{TiO}_{2}$ NPs stimulated IL- $1 \beta$ release with good dosedependency. Previous studies have shown that several types of NPs (e.g., $\mathrm{TiO}_{2}, \mathrm{SiO}_{2}$, and $\mathrm{Ag}$ ) as well as crystalline silica simulate IL-1 $\beta$ release by inflammasome activation, which can be

\section{REFERENCES}

Adam, N., Schmitt, C., Galceran, J., Companys, E., Vakurov, A., Wallace, R., et al. (2014). The chronic toxicity of $\mathrm{ZnO}$ nanoparticles and $\mathrm{ZnCl} 2$ to Daphnia magna and the use of different methods to assess nanoparticle aggregation and dissolution. Nanotoxicology 8, 709-717. doi: 10.3109/17435390.2013.82 2594

Amara, S., Slama, I. B., Mrad, I., Rihane, N., Khemissi, W., El Mir, L., et al. (2014). Effects of zinc oxide nanoparticles and/or zinc chloride on biochemical parameters and mineral levels in rat liver and kidney. Hum. Exp. Toxicol. 33, 1150-1157. doi: 10.1177/0960327113510327

Braakhuis, H. M., Park, M. V., Gosens, I., De Jong, W. H., and Cassee, F. R. (2014). Physicochemical characteristics of nanomaterials that affect pulmonary inflammation. Part. Fibre Toxicol. 11:18. doi: 10.1186/1743-8977-11-18 triggered by the phagocytosis-related events including NP uptake and phagosomal leakage or endoplasmic reticulum stress (Yazdi et al., 2010; Sandberg et al., 2012; Simard et al., 2015). Thus, no significant changes in IL-1 $\beta$ concentration by fast-dissolving NPs and their metal chlorides imply that those substances cannot stimulate inflammasome activation, which might be due to the fast dissolution of NPs inside lysosomes (Cho et al., 2013a). The minimal changes of IL- 8 by both NPs and metal chlorides observed in this study might imply that these materials does not stimulate IL- 8 release at sub-lethal doses, but our previous study showed that the lethal dose of $\mathrm{ZnO}$ and $\mathrm{CuO}$ NPs can stimulate IL-8 release in A549 cells (Cho et al., 2013a).

\section{CONCLUSION}

The comparison of cytotoxicity caused by fast-dissolving NPs and their constituent metal ions showed both similarities and differences. Successful development of STR for fast-dissolving NPs need precise calculation of the intrinsic toxic potential of its constituent metal ions and evaluation of similarity of doseresponse curve between NP and metal ion. In this perspective, this result shows that $\mathrm{CoO}$ and $\mathrm{CuO}$ NPs can be simply predicted by its toxic potential of $\mathrm{Co}$ and $\mathrm{Cu}$ ion but $\mathrm{ZnO}$ NPs need more parameters for the prediction which warrant further studies. This may be mainly due to the differential mechanism of intracellular uptake of these substances and their interaction with detoxification molecules such as metallothionein.

\section{AUTHOR CONTRIBUTIONS}

Participated in the experimental design and data analysis: JJ, S-HK, and W-SC. Conducted the experiments: JJ and S-HK, with help of SL, D-KL, YH, and SJ. Wrote the first draft of the manuscript: JJ and S-HK. Contributed to the writing of the manuscript: SL, D-KL, YH, SJ, and W-SC. All authors read and approved the final version of the manuscript.

\section{FUNDING}

This study was supported by grants from the Dong-A University.

Bulcke, F., and Dringen, R. (2015). Copper oxide nanoparticles stimulate glycolytic flux and increase the cellular contents of glutathione and metallothioneins in cultured astrocytes. Neurochem. Res. 40, 15-26. doi: 10.1007/s11064-0141458-0

Cho, W. S., Duffin, R., Bradley, M., Megson, I. L., Macnee, W., Lee, J. K., et al. (2013a). Predictive value of in vitro assays depends on the mechanism of toxicity of metal oxide nanoparticles. Part. Fibre Toxicol. 10:55. doi: 10.1186/17438977-10-55

Cho, W. S., Duffin, R., Howie, S. E., Scotton, C. J., Wallace, W. A., Macnee, W., et al. (2011). Progressive severe lung injury by zinc oxide nanoparticles; the role of $\mathrm{Zn} 2+$ dissolution inside lysosomes. Part. Fibre Toxicol. 8:27. doi: 10.1186/ 1743-8977-8-27

Cho, W. S., Duffin, R., Poland, C. A., Duschl, A., Oostingh, G. J., Macnee, W., et al. (2012a). Differential pro-inflammatory effects of metal oxide nanoparticles 
and their soluble ions in vitro and in vivo; zinc and copper nanoparticles, but not their ions, recruit eosinophils to the lungs. Nanotoxicology 6, 22-35. doi: 10.3109/17435390.2011.552810

Cho, W. S., Duffin, R., Poland, C. A., Howie, S. E., MacNee, W., Bradley, M., et al. (2010). Metal oxide nanoparticles induce unique inflammatory footprints in the lung: important implications for nanoparticle testing. Environ. Health Perspect. 118, 1699-1706. doi: 10.1289/ehp.1002201

Cho, W. S., Duffin, R., Thielbeer, F., Bradley, M., Megson, I. L., Macnee, W., et al. (2012b). Zeta potential and solubility to toxic ions as mechanisms of lung inflammation caused by metal/metal oxide nanoparticles. Toxicol. Sci. 126, 469-477. doi: 10.1093/toxsci/kfs006

Cho, W. S., Kang, B. C., Lee, J. K., Jeong, J., Che, J. H., and Seok, S. H. (2013b). Comparative absorption, distribution, and excretion of titanium dioxide and zinc oxide nanoparticles after repeated oral administration. Part. Fibre Toxicol. 10:9. doi: 10.1186/1743-8977-10-9

Colognato, R., Bonelli, A., Ponti, J., Farina, M., Bergamaschi, E., Sabbioni, E., et al. (2008). Comparative genotoxicity of cobalt nanoparticles and ions on human peripheral leukocytes in vitro. Mutagenesis 23, 377-382. doi: 10.1093/mutage/ gen 024

Cuillel, M., Chevallet, M., Charbonnier, P., Fauquant, C., Pignot-Paintrand, I., Arnaud, J., et al. (2014). Interference of $\mathrm{CuO}$ nanoparticles with metal homeostasis in hepatocytes under sub-toxic conditions. Nanoscale 6, 1707-1715. doi: 10.1039/c3nr05041f

Darolles, C., Sage, N., Armengaud, J., Malard, V., (2013). In vitro assessment of cobalt oxide particle toxicity: identifying and circumventing interference. Toxicol. In Vitro 27, 1699-1710.

Donaldson, K., Schinwald, A., Murphy, F., Cho, W. S., Duffin, R., Tran, L., et al. (2013). The biologically effective dose in inhalation nanotoxicology. Acc. Chem. Res. 46, 723-732. doi: 10.1021/ar300092y

Garcia-Gomez, C., Babin, M., Obrador, A., Alvarez, J. M., and Fernandez, M. D. (2014). Toxicity of $\mathrm{ZnO}$ nanoparticles, $\mathrm{ZnO}$ bulk, and $\mathrm{ZnCl}(2)$ on earthworms in a spiked natural soil and toxicological effects of leachates on aquatic organisms. Arch. Environ. Contam. Toxicol. 67, 465-473.

Hahn, S. H., Yoo, O. J., and Gahl, W. A. (2001). Effect of metal ions on the stability of metallothionein in the degradation by cellular fractions in vitro. Exp. Mol. Med. 33, 32-36. doi: 10.1038/emm.2001.7

Holder, A. L., Goth-Goldstein, R., Lucas, D., and Koshland, C. P. (2012). Particleinduced artifacts in the MTT and LDH viability assays. Chem. Res. Toxicol. 25, 1885-1892. doi: 10.1021/tx3001708

Jeong, J., Han, Y., Poland, C. A., and Cho, W. S. (2015). Response-metrics for acute lung inflammation pattern by cobalt-based nanoparticles. Part. Fibre Toxicol. 12:13. doi: 10.1186/s12989-015-0089-1

Kim, Y. H., Fazlollahi, F., Kennedy, I. M., Yacobi, N. R., Hamm-Alvarez, S. F., Borok, Z., et al. (2010). Alveolar epithelial cell injury due to zinc oxide nanoparticle exposure. Am. J. Respir. Crit. Care Med. 182, 1398-1409. doi: 10.1164/rccm.201002-0185OC

Kroll, A., Pillukat, M. H., Hahn, D., and Schnekenburger, J. (2012). Interference of engineered nanoparticles with in vitro toxicity assays. Arch. Toxicol. 86, 1123-1136. doi: 10.1007/s00204-012-0837-Z

Liu, R., Liu, H. H., Ji, Z., Chang, C. H., Xia, T., Nel, A. E., et al. (2015). Evaluation of toxicity ranking for metal oxide nanoparticles via an in Vitro dosimetry model. ACS Nano 9, 9303-9313. doi: 10.1021/acsnano.5b04420
Oberdorster, G., Oberdorster, E., and Oberdorster, J. (2005). Nanotoxicology: an emerging discipline evolving from studies of ultrafine particles. Environ. Health Perspect. 113, 823-839.

Ponti, J., Sabbioni, E., Munaro, B., Broggi, F., Marmorato, P., Franchini, F., et al. (2009). Genotoxicity and morphological transformation induced by cobalt nanoparticles and cobalt chloride: an in vitro study in Balb/3T3 mouse fibroblasts. Mutagenesis 24, 439-445. doi: 10.1093/mutage/ gep027

Puzyn, T., Leszczynska, D., and Leszczynski, J. (2009). Toward the development of "nano-QSARs": advances and challenges. Small 5, 2494-2509. doi: 10.1002/ smll.200900179

Rosslein, M., Elliott, J. T., Salit, M., Petersen, E. J., Hirsch, C., Krug, H. F., et al. (2015). Use of cause-and-effect analysis to design a high-quality nanocytotoxicology assay. Chem. Res. Toxicol. 28, 21-30. doi: 10.1021/ tx500327y

Rushton, E. K., Jiang, J., Leonard, S. S., Eberly, S., Castranova, V., Biswas, P., et al. (2010). Concept of assessing nanoparticle hazards considering nanoparticle dosemetric and chemical/biological response metrics. J. Toxicol. Environ. Health A 73, 445-461. doi: 10.1080/15287390903489422

Sandberg, W. J., Lag, M., Holme, J. A., Friede, B., Gualtieri, M., Kruszewski, M., et al. (2012). Comparison of non-crystalline silica nanoparticles in IL-1beta release from macrophages. Part. Fibre Toxicol. 9:32. doi: 10.1186/1743-89779-32

Semisch, A., Ohle, J., Witt, B., and Hartwig, A. (2014). Cytotoxicity and genotoxicity of nano - and microparticulate copper oxide: role of solubility and intracellular bioavailability. Part. Fibre Toxicol. 11:10. doi: 10.1186/1743-897711- 10

Simard, J. C., Vallieres, F., de Liz, R., Lavastre, V., and Girard, D. (2015). Silver nanoparticles induce degradation of the endoplasmic reticulum stress sensor activating transcription factor- 6 leading to activation of the NLRP3 inflammasome. J. Biol. Chem. 290, 5926-5939. doi: 10.1074/jbc.M114.61 0899

Wiseman, D. A., Wells, S. M., Wilham, J., Hubbard, M., Welker, J. E., and Black, S. M. (2006). Endothelial response to stress from exogenous $\mathrm{Zn} 2+$ resembles that of NO-mediated nitrosative stress, and is protected by MT-1 overexpression. Am. J. Physiol. Cell Physiol. 291, C555-C568.

Yazdi, A. S., Guarda, G., Riteau, N., Drexler, S. K., Tardivel, A., Couillin, I., et al. (2010). Nanoparticles activate the NLR pyrin domain containing 3 (Nlrp3) inflammasome and cause pulmonary inflammation through release of IL-1alpha and IL-1beta. Proc. Natl. Acad. Sci. U.S.A. 107, 19449-19454. doi: $10.1073 /$ pnas. 1008155107

Conflict of Interest Statement: The authors declare that the research was conducted in the absence of any commercial or financial relationships that could be construed as a potential conflict of interest.

Copyright (c) 2018 Jeong, Kim, Lee, Lee, Han, Jeon and Cho. This is an open-access article distributed under the terms of the Creative Commons Attribution License (CC BY). The use, distribution or reproduction in other forums is permitted, provided the original author(s) or licensor are credited and that the original publication in this journal is cited, in accordance with accepted academic practice. No use, distribution or reproduction is permitted which does not comply with these terms. 